\title{
Operation and Control of Multiterminal HVDC Grids Following the Loss of an Onshore Converter
}

\begin{abstract}
B.Silva, Student Member, IEE
ulti-Terminal DC (MTDC) grid
Abstract-- A fully operational Multi-Terminal DC (MTDC) grid will play a key role for the creation of AC systems interconnection and to integrate offshore wind farms. Disturbances (at both $\mathrm{AC}$ and DC side) may culminate in the sudden disconnection of onshore HVDC-VSC (High Voltage Direct Current - Voltage Source Converter). To continue operating the DC grid under these conditions, the development of control functionalities is required. A communication-free advanced control scheme is proposed to be used as a supplementary local control acting at VSC level and aiming on providing fast active power accommodation in the DC grid, culminating on the mitigation of the resulting DC overvoltage. The implementation of the proposed control mechanisms exploits a set of coordinated local control rules at the converter stations and at wind turbines (WT) level. The performance of the proposed strategies is discussed and assessed through numerical simulation in the paper.
\end{abstract}

Index Terms-- HVDC, Multi-Terminal DC grids, Offshore Wind Power.

\section{INTRODUCTION}

$\mathrm{T}$

HE Climate change is forcing governments to reduce

$\mathrm{CO}_{2}$ emissions. The adoption of Renewable Energy Systems (RES) for electricity generation gives a contribution on coping with ambitious targets such as the 2020-20 plan that has been adopted in Europe. In this case, $30 \%$ of the electricity should be attained through RES by 2020 . Hydro generation has been the most adopted RES during the past five to six decades and achieved satisfactory maturity level from the technological perspective. However, further hydro integration is strongly constrained by the water availability, river courses and also a complex set of environmental assessment studies to achieve construction

This work is funded (or part-funded) by the ERDF - European Regional Development Fund through the COMPETE Programme (operational programme for competitiveness) and by National Funds through the FCT Fundação para a Ciência e a Tecnologia (Portuguese Foundation for Science and Technology) within project «FCOMP - 01-0124-FEDER-022701», by FCT under PhD grant SFRH/BD/61600/2009 and by FCT Project COMUTEDC ref: PTDC/EEI-EEL/2053/2012 financed by Operational Programme Thematic Factors of Competitiveness (COMPETE) and the National Strategic Reference Framework (QREN).

The authors are with the INESC TEC-INESC Technology and Science (formerly INESC Porto) and FEUP - Faculdade de Engenharia da Universidade do Porto, R. Dr. Roberto Frias, 378, 4200-465 Porto, Portugal (e-mails: bsilva@inescporto.pt, cmoreira@inescporto.pt, hleite@fe.up.pt) license. On the last two decades, huge development on the wind power industry culminated on a massive integration level, reaching $94 \mathrm{GW}$ in Europe [1]. Nevertheless, the massive penetration led to scarcity of favorable spots for further integration together with strong restriction on acquiring licenses for grid connection.

Still being far from the committed targets for renewable generation, alternatives RES implantation has been under study. One very audacious but simultaneously very promising solution is to install massive amount of wind generation at offshore level, namely in the Northern Sea where the resource availability is very favorable. However, power transmission is the main challenge for offshore wind power development. The offshore Wind Farm (WF) requires a submarine cable circuit to transmit the generated power to the onshore AC grids. However, capacitive effects of shielded submarine cables require significant reactive (inductive) power compensation and over a certain length become physically impossible to transmit AC power.

Alternatively, the adoption of High Voltage Direct Current (HVDC) technology enables power transmission over long length cable circuits. HVDC technology is being under commercial operation since mid-1950 decade. Notwithstanding, the power electronic converter developments has enhanced the HVDC capacities and capabilities. Nowadays there are two major technologies commercially available, differing mainly on the power electronic converters typology: (1) The Line-Commuted Converts (LCC), based on thryristor valves, mainly used for bulk power transmission. (2) The Voltage Source Converters (VSC) based on IGBT forcecommuted valves, offering an increased flexibility of operation by allowing independent control of active and reactive power, black-start capability, small harmonic filter, voltage support, bidirectional power flows and the creation of Multiterminal DC (MTDC) grids.

An additional driver to the implantation of offshore WF is the need on increasing the system adequacy, the security of supply and the creation a single European Energy Market [2]. These drivers require the deployment of further electrical connections by land and by the sea through the adoption of offshore grids $[3,4]$. In both cases, offshore interconnections are expected to provide two main requirements: the support to exchange power between AC areas and offshore wind power integration. The point-to-point offshore connections present important drawbacks related to reliability and flexibility of operation. Criteria such flexibility, redundancy and reduction of the power not supplied to onshore grids in DC disturbance cases are also 
drivers for the development of the multiterminal grids [5-8]. On the other hand, one of the biggest bottlenecks for the MTDC grid deployment is related with the unavailability of commercial DC breakers for high power specification. Despite having DC cable fault is statistically very unlike to happen, the DC grid needs breakers for a safe operation and even reconfiguration. Nevertheless, some research has been performed in this specific area and recently a major manufacturer has announced the development of DC breakers [9].

Regarding MTDC grids, an approach for its operation, control and dynamic simulation purposes is presented in [8]. In [10], the authors presented an autonomous control strategy based on active power-DC voltage droop control to be used on onshore VSC stations as an alternative to master-slave solutions supported by communications. This control scheme allows for autonomous MTDC grid operation and sharing offshore WF power fluctuations among the onshore VSC mitigating its effects without relying in fast communication channels. In line with the aforementioned drivers, the MTDC should perform as a virtual power plant with several injection points contributing with ancillary service provision to support onshore AC grid operation in case od disturbances. In [11] authors have proposed an enhanced control scheme endowing the MTDC grid, offshore WF and healthy AC areas on providing primary frequency control. Additionally, the adoption of local controllers assured adequate response time for allowing the provision of inertial emulation by the offshore WF.

A very common requirement for onshore wind farm, that may also be required to offshore WF, consists on the provision of Fault Ride-Through (FRT) capability for onshore AC grid faults. In this particular topic some research has been conducted for point-to-point HVDC connected offshore WF

$[12,13]$.

Following an onshore AC grid fault, a common challenge of HVDC transmission systems is related with the DC overvoltage occurrence due to the loss of active power extraction capability. In fact, the fault occurrence impacts on the $\mathrm{AC}$ voltage profile. Thus, the correspondent onshore HVDC-VSC increases its current output to counteract against the voltage sag, attempting to transmit the pre-disturbance power amount. However, the VSC have current limits and once it is reached, during the AC voltage sag, the active power will come also limited reducing the HVDC-VSC power extraction capability. The constant incoming offshore power associated with the loss power extraction capability will impact on the DC grid by provoking a power imbalance that causes a DC overvoltage. In line with the aforementioned phenomena, [12, 13] identify the need of mechanisms for DC grid active power balance to avoid or reduce the overvoltage magnitude. In [12], authors have assessed a typical time of $25 \mathrm{~ms}$ during which the DC grid active power balance should occur. Unless power dissipation is used, such narrow time requires the adoption of fast communication channels to perform active power reduction strategies at offshore WF level. Alternatively, the authors proposed also the employment of a chopper circuit on the HVDC link to dissipate some of the non-delivered power thus controlling the overvoltage magnitude. Also alternative solutions were proposed involving de-loading of the WF on fault detection (requiring communication). Another possible solution is based on an advanced control scheme implemented at the offshore HVDCVSC taking advantage of the DC overvoltage occurrence to quickly reduce the active power output at the WF level. This strategy does not require fast communication, since its use is strongly inadvisable from the reliability perspective. In [13], authors propose a control scheme to be implemented at offshore HVDC-VSC based on a voltage-droop, mimicking the DC voltage rise into AC offshore voltage reduction. Thus, offshore WF generators equipped with FRT capability are able to reduce the active power injection.

In line with the development of autonomous control concepts for MTDC grids in several situations, for this paper aims to demonstrate the possibility of extending the referred control concepts in order to develop a set of controllers to be housed at HVDC-VSC stations as well as at the offshore wind turbine level in order to assure the necessary conditions for secure operation following the sudden loss of an onshore converter station. The performance of the proposed control concepts are extensively tested through numerical simulations.

\section{MODELING AND CONTROL OF MTDC GRID}

The MTDC grid is based on a bipolar DC cable infrastructure that provides the interconnection of "N" offshore Wind Farms (WF) to "M" mainland collection points interconnected to the onshore grids. Adequate models are required to evaluate the dynamic behavior of the overall MTDC grid, including the HVDC-VSC stations and offshore wind farms. The modeling approach for this specific case is very similar to the proposed in authors' previous communication [11]. Nonetheless, some enhancements are required in order to include the representation of the HVDCVSC current injection limit. Also, it is important to highlight that the major dynamic phenomena to be analyzed in this paper consists on the loss of an onshore converter which is mainly associated to faults occurring in the mainland $\mathrm{AC}$ grid $[8,11,14]$ or to internal converter faults. The specific issue of DC-side faults was not assessed in this paper. For this specific analysis a different modeling approach is required, namely modeling the HVDC-VSC topology in more detail.

\section{A. Multiterminal HVDC grid}

The MTDC grid was assumed to be bipolar (two cables with symmetrical DC voltages - nominal voltage $\left.\pm V_{n}\right)$. The connections within the DC grid are assured by the cable circuit which was modeled by concentrated parameter (cable resistance and inductance) according with the approach introduced in [8]. The MTDC grid is then modeled by the corresponding algebraic and state equations..

\section{B. HVDC Converters}

Both onshore and offshore converters are VSC technology. The converters were modeled using an RMS dynamic control models, which is a good representation of its behavior independently of its internal topology. So, fast switching transients, harmonics and inverter losses are neglected similarly to the approaches followed in [6], [15]. The differences between the converters (onshore and offshore) were focused on their control strategies which are presented next.

1) Onshore VSC: The onshore converter station is responsible for controlling the voltage of the DC-side converter capacitors 'bank (see Fig. 1). The converter dynamics were 
modelled by proportional-integral (PI) controllers. Since VSC allow independent control of active and reactive power, two independent control loops were implemented. The converters model were implemented in $d-q$ synchronous reference frame following the approaches suggested on [15]. According to the scheme presented on Fig. 1, the error between the $V q_{r e f}$ and $V q$ (the reference and the actual value, respectively) generates the $i q_{r e f}$ current reference. Then, the error between the $i q_{r e f}$ and the actual $i q$ value generates the $V q$ ' output. The analogous process is adopted to obtain the $V d^{\prime}$ 'voltage reference. However, a slight difference exists in the way to attain the $i d_{r e f}$ current reference (see Fig. 1). In fact, the $i d_{r e f}$ current is given by the error between the actual VSC DC-side voltage $\left(V_{D C}\right)$ and a reference DC voltage value $\left(V_{D C r e f}\right)$ after passing through a PI controller as depicted in the same figure.

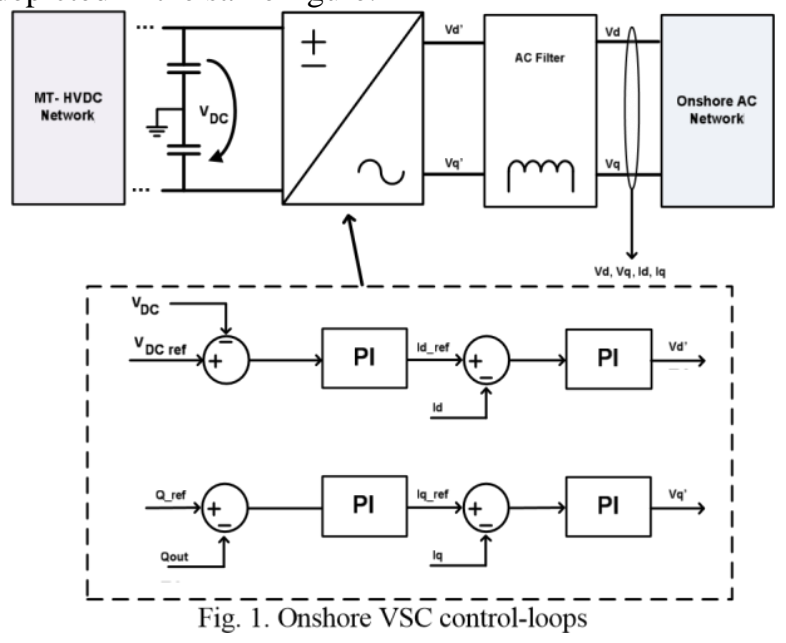

2) Offshore VSC: The offshore converter interfaces the offshore AC grid with the DC cable circuit. It is responsible by imposing the AC-side voltage and frequency and delivers all the offshore WF generated power to the DC grid [10]. The control scheme for the offshore VSC is represented in Fig. 2. Once again, PI controllers were adopted. The $V d$ and $V q$ errors generate the $i d_{r e f}$ and $i q_{r e f}$ references that are compared with the existing value in the so-called inner current loop, generating the $V d^{\prime}$ and $V q^{\prime}$ voltage output.

\section{Current limits on the HVDC-VSC}

The study of HVDC-VSC systems under disturbed conditions requires the adequate representation of current limits constraints. In fact, converters current limits associated with AC grid residual voltage profile dictates the power extraction capability. For the analysis performed in this paper it is mandatory to perform such modeling since it may also limit the healthy onshore VSC power extraction capability. Modeling of current limits in HVDC-VSC stations followed the approach described in [12].
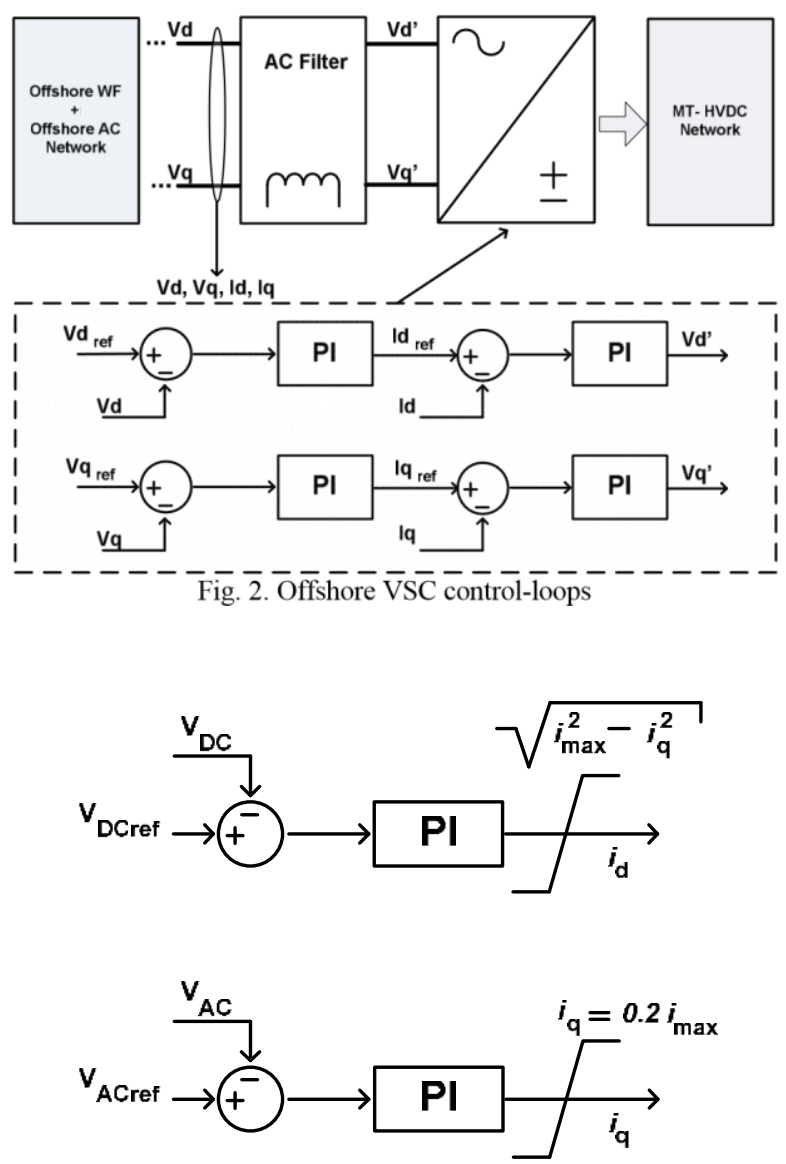

Fig. 3. HVDC-VSC current limiters

The $i_{d}(d$ axis current component) is associated with the active power control and the $\mathrm{i}_{\mathrm{q}}$ (q axis current component) is related with the reactive current injection. For the purposes of the study conducted in this paper, the converter reactive current capability was fixed. The $\mathrm{d}$ axis current limit can be determined taking into account the converter maximum admissible current $i_{\max }$, as it is shown in Fig. 3.

\section{Operation and Control of the MTDC grid}

The onshore converters are responsible for controlling the voltage profile at its DC-side terminals. On the other side, offshore converters are responsible for delivering all the generated offshore WF power to the DC-grid. Therefore, appropriated DC voltage magnitudes should be maintained at each onshore converter station in order to allow proper power sharing among converters in case of power variations such as the ones occurring at the offshore WF level.A possible solution consist on the use of a droop control approach in order to determine the DC voltage reference at each onshore converter station as a function of the injected power in the AC system In this case, DC power variations are shared among the overall onshore converter stations [10]. The control rule can be expressed by the following equation:

$$
V_{D C}=V_{D C \text { set }}+k_{p v} \times P_{o u t}
$$

where $V_{D C}$ and $k_{p v}$ are configurable values that can be parameterized in each onshore VSC according to the specific 
operation of the AC grid. Basically, this relation dictates that the voltage at onshore VSC will depend on the power amount delivered to the AC grid. The parameter ${ }_{D C \text { set }}$ can be remotely adjusted to act as a dispatch variable.

\section{E. Wind Generator Model}

The offshore wind generators are interconnected to the offshore converter by AC submarine cable circuit. From the modeling perspective offshore generators are similar to onshore. Without loss of generality, a Permanent Magnet Synchronous Generator (PMSG) interfaced by a full AC/DC/AC converter has been considered. The mechanical, aerodynamic and electrical models were implemented according to the suggested in [16].

\section{LOSS OF AN ONSHORE HVDC-VSC}

In normal operation, HVDC-VSC stations are connected to the MTDC grid and to the mainland AC grid. However, some circumstances may lead to onshore HVDC-VSC stations blocking or disconnection. These events are usually associated to unwanted tripping events or to protective relaying functions that may dictate the converter tripping to protect the HVDCVSC itself or to protect the DC or AC network. The permanent disconnection of an onshore HVDC-VSC, normally named as loss of the converter, impacts the normal operation of the DC grid by affecting the overall power extraction capability in two different situations:

- Transitorily - if the remaining HVDC-VSC stations have margin to accommodate the non-delivered power resulting from the loss of one HVDC-VSC. In this situation a power imbalance may transitorily occur in the DC grid until the remaining HVDC-VSC stations increase their power extraction.

- Permanently - if the remaining HVDC-VSC do not have margin to accommodate the all the non-delivered power provoked by the loss of one HVDC-VSC. In this situation a permanent power imbalance will take place in the DC grid. Thus, a control strategy must be envisioned in order to promote the DC grid power balance and eventually reduce power generation in the offshore WF level.

The impacts of DC grid power imbalance due to the loss of a converter station may lead to DC overvoltages on the DC grid. Therefore, fast active power dissipation or offshore WF incoming power regulation mechanisms must exist to guarantee that the DC grid voltage does not overreach a given maximum admissible value.

The adoption of chopper resistors to promote power equilibrium during permanent loss of a HVDC-VSC is not adequate since these devices have a limited energy dissipation capacity. Normally, the maximum energy that a chopper resistor can dissipate is related with the thermal limits of the own resistor and is limited by a thermal protection. Thus, in the case of a permanent loss of an onshore HVDC-VSC and considering that there is not enough margins in the remaining onshore HVDCVSC to accommodate the non-delivered power, an advanced control scheme must assure that the offshore wind power is reduced accordingly aiming on avoiding DC overvoltage occurrence. However, as previously mentioned, the time frame to promote the incoming power reduction to avoid overvoltage occurrence is very tight. Therefore, it is necessary to design an advanced control scheme to handle two non-simultaneous objectives. The first objective consists on the capability of fast power dissipation to guarantee the fast DC power equilibrium and maintain DC voltage profile within specific margins. The second objective consists on the capability of providing power reduction for a larger temporal framework (steady state power reduction). The scheme illustrated in Fig. 4 represents the power dissipation, accommodation or reduction characteristics that are necessary as well as the time frame that is necessary to deal with the permanent loss of an onshore HVDC-VSC. Aftermath the loss of onshore HVDC-VSC it is necessary to reduce or dissipate a

high amount of power very quickly since the healthy onshore HVDC-VSC may not be able to respond quickly enough to avoid overvoltage occurrence. However, offshore wind power reduction might still be necessary to achieve the DC grid power balance, special in operational scenarios where onshore converters are near their rated capacity.

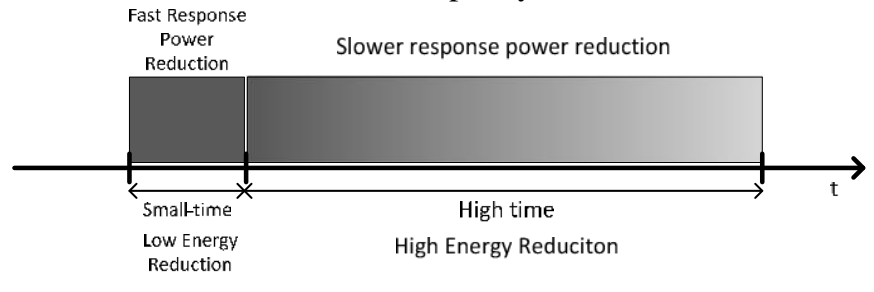

Fig. 4. Response characteristics of power reduction mechanisms

IV.

CONTROL STRATEGIES FOR OFFSHORE ACTIVE POWER REGULATION

In this paper it is proposed a communication-free control scheme to be implemented at offshore HVDC-VSC level, allowing offshore WT locally react following the loss of the onshore HVDC-VSC. This control scheme takes advantage of the $\mathrm{DC}$ voltage rise to mimic an offshore $\mathrm{AC}$ grid frequency rise through the adoption of a DC voltage-offshore AC frequency droop. Modifications on WT control is also required to guarantee that the offshore WF is able to respond to frequency increase by reducing the each WT power delivery. Two strategies were tested. First, WT were set to respond to frequency deviations similarly to the approach described in [16]. The second consisted on combining the DC chopper (located at WT) operation with the pitch control. This control scheme takes advantage of the DC chopper (which is normally set to respond to $\mathrm{AC}$ voltage sag during fault situations) to quickly dissipate some of the generated power (at each WT chopper), thus contributing to promotion of the DC voltage control at the MTDC grid. Bearing in mind that choppers have an associated maximum energy dissipation capacity, blade's pitch control should also collaborate by reducing the generated active power. Thus, after chopper disconnection, offshore WT should be steadily operating in a new point, injecting less power. The additional controls required at each component are presented in the next sub-sections. 


\section{A. Offshore HVDC-VSC Control Enhancements}

Offshore converters are controlled on a grid former philosophy from the AC offshore grid perspective. They are able to control the offshore $\mathrm{AC}$ voltage magnitude and impose the AC offshore grid frequency. The modifications on the offshore converter's control consist on endowing them with a droop control to set the AC frequency proportionally to the DC voltage magnitude. This new control loop is expressed in Fig. 5.

The DC voltage profile VDC is compared with the reference value $\mathrm{VDC}_{\text {ref }}$ (the $\mathrm{DC}$ voltage magnitude in steady operation). The positive error generated (overvoltage) is proportionally transformed in a frequency deviation (increase) at the offshore grid by the $\mathrm{K}_{\mathrm{DC} / \mathrm{f}}$ droop gain.

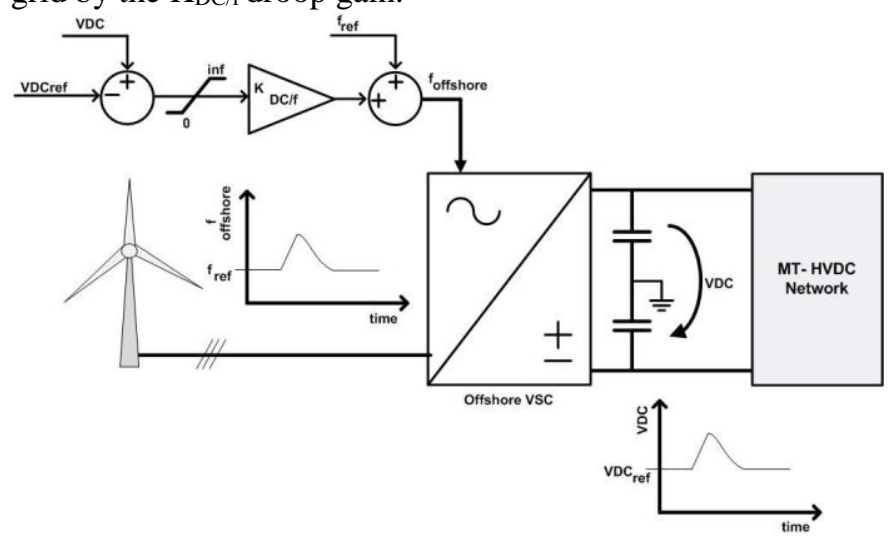

Fig. 5. AC offshore frequency control based on DC overvoltage.

\section{B. Wind Turbine Control Enhancements}

Modifications on the control loops of wind turbines are required to attain the desired response regarding active power reduction following the $\mathrm{AC}$ offshore frequency increase, according to the control mechanism presented in the previous sub-section. As previously mentioned the control strategies for active power reduction will depend on chopper energy dissipation and blade's pitch angle adjustment.

\section{1) Active Power Reduction through Pitch Angle Control}

The control scheme for provision of blade's pitch adjustment is presented for a PMSG interfaced by full converter on Fig. 6 .

The offshore frequency $f_{\text {off }}$ is compared with the offshore frequency reference $f_{\text {refoff. }}$ The error generated is adapted to a rotational speed increment $\Delta \omega$ by the $\mathrm{K}_{\mathrm{pf}}$ frequency-speed droop. The new rotational speed $\omega$ will correspond to a new power reference $\mathrm{P}_{\text {ref }}$ that will give origin to a new blade pitch angle $\beta$.
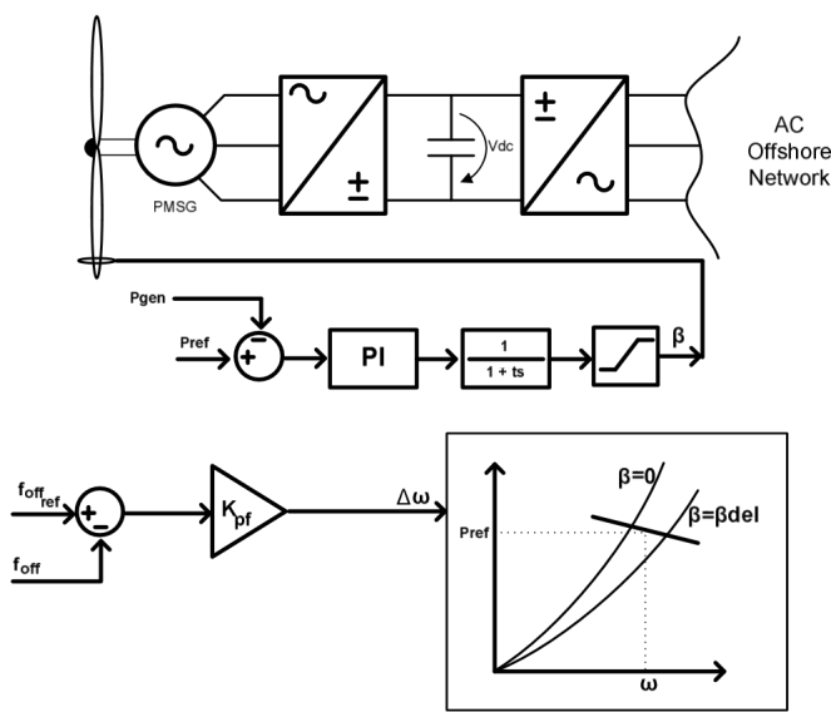

Fig. 6. Control scheme for active power reduction through WT pitch control.

\section{2) Active Power Dissipation on Chopper Resistor}

The other possible solution for offshore WF to reduce the active power consists on using the WT chopper to dissipate active power resulting on a fast reduction of the active power delivered by each WT to the AC offshore grid. The control scheme for active chopper power dissipation according to frequency increase is depicted in Fig. 7.

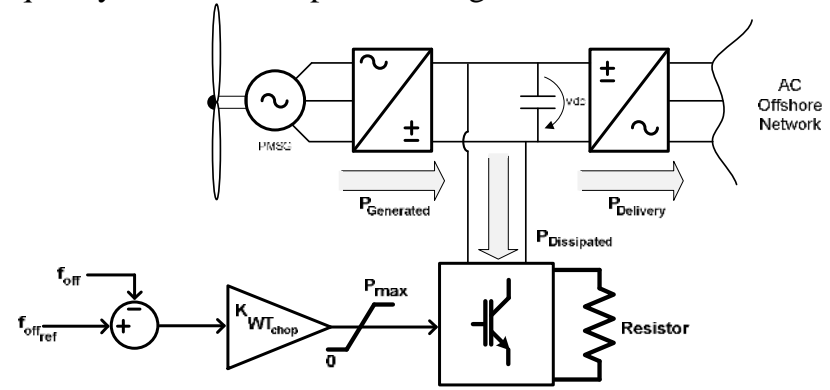

Fig. 7. Control scheme for active power dissipation with DC chopper resistor in PMSG.

The chopper resistor is set to dissipate power according to the frequency error. So, the error generated between offshore frequency $\mathrm{f}_{\text {off }}$ (imposed by the offshore HVDC-VSC and measured at the WT terminals) and the $\mathrm{f}_{\text {offree }}$ is adapted by a

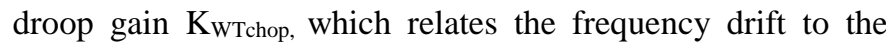
active power to be dissipated in the chopper. Then, this signal is sent to the chopper controller to control the power to be dissipated. An additional protection has also been modeled to limit the maximum energy dissipated that is associated with the chopper thermal limits. According to PMSG WT manufacturers, choppers are sized to withstand the maximum turbine power for five seconds. In a two megawatt-class WT it corresponds to a maximum energy of $10 \mathrm{MJ}$. The total energy calculation was attained by integrating the power dissipation achieved at the chopper resistors.

\section{ASSESSMENT OF POWER REDUCTION CONTROL SCHEMES UNDER LOSS OF AN ONSHORE HVDC-VSC}

A set of simulations were performed to assess the performance of the previously presented control schemes on a 
MTDC grid following the sudden the loss of an onshore converter. The adopted simulation platform as well as the HVDC-VSC control loops for basic operation is presented in [11]. The MTDC grid is depicted in Fig. 8. It consists in a " $\mathrm{H}$ " topology MTDC grid interconnecting two offshore WF equipped with PMSG to two onshore AC systems. The loss of an Onshore Converter consists on the permanent disconnection of Area\#1 or Area \#2 HVDC-VSC. The simulations were carried out in Matlab/Simulink in a MTDC grid model platform developed for dynamic stability studies and envisioned testing the behavior of power reduction schemes through the previously presented offshore frequency increase proportionally to the DC voltage increase. Regarding the offshore wind turbine-level, two power reduction mechanisms were considered:

- Case A - Wind turbines configured with pitch control

- Case B - Wind turbines configured with pitch control and chopper resistor

For the reason previously mentioned (related with the lack of chopper resistor permanent power dissipation capability, presented in Section III), the case of having just a chopper resistor at WT level for power equilibrium promotion was not considered. Without lack of completeness the simulations carried out consisted on the loss of Area \#1 onshore HVDCVSC at $\mathrm{t}=0 \mathrm{~s}$ (see Fig. 8) The results obtained for both case A and case B are depicted in the Fig. 9 to Fig. 13.

The power injections at each MTDC grid terminals are depicted in Fig. 9. The power injection at the disconnected onshore Area \#1 VSC becomes null at the moment of disconnection $(\mathrm{t}=0 \mathrm{~s})$. Some of the non-delivered power is channeled to the onshore Area \#2 VSC due to the existence of the DC voltage/Active power droop control. However, its value is limited to the maximum converter capacity (defined as 1.5 p.u. in current, limited according to the scheme presented in Fig. 3). It is also possible to observe that offshore

WF are able to permanently reduce some of the predisturbance injected power.. The main difference between the case A and case $B$ are related with the settling time, oscillations and active power overshoot behavior. In fact, the adoption of choppers at wind turbine level (case B) promotes a steadier power injection behavior. This fact is also noticeable on the DC voltage behavior results, depicted in Fig. 10. The DC voltage profile evolution is quite identical among offshore HVDC-VSC terminals and Area \#1 terminal. However, the DC voltage at the onshore Area \#2 VSC differs from the other terminal voltages' since the healthy onshore Area \#2 HVDCVSC is responsible by controlling its value by collecting more active power from the MTDC grid a seen on Fig. 9. Regarding the comparison of overvoltage magnitude it becomes notorious that the case A solution is not able to fully comply with the DC voltage control by allowing the DC voltage overpass the maximum admissible value of 1.2 p.u. This fact is related with the slow response of pitch control that has a mechanical time delay inherent to the blades' pitch servomotors. The addition of chopper resistors (case B) not only promotes a steadier DC voltage behavior but also reduces the DC overvoltage magnitude, keeping it below the maximum admissible value.

Regarding the offshore frequency behavior, the results depicted on the Fig. 11illustrates that the frequency disturbance on each AC offshore grid were proportionally induced from the DC voltage behavior. Once again, it is noticeable the difference between case A and case B even in the frequency behavior. In fact the smaller frequency disturbance achieved with the implementation in the case B is easily attained by power electronic converters and for applications with other kind of wind generator technologies (not fully electronic-interfaced, such as fixed speed generator or doubly-fed induction generators) can induce lower speed disturbances to the generators.

The evolution of wind turbine pitch angle value has also been monitored being its evolution illustrated in Fig. 13. In both cases, wind turbine pitch angle was regulated to achieve the desired generated power reduction. Nonetheless, in case A, where the generator power reduction was purely achieved by pitch angle increase, it is possible to verify a significant rate of change on the pitch angle. Bearing in mind that the pitch angle regulation is achieved by servo-motors that moves the wind turbines' blades in an axial movement, these situations can be undesired from the mechanical stress perspective. Nevertheless, a combined approach exploiting the use of chopper resistors in the power reduction mechanism is able to reduce the pitch angle variations and consequently eventual mechanical stress.

Finally, the results depicted in Fig. 13, present the interactions of the active power at wind farms level. On the first graphic, for the case A, the power reduction is achieved at the generator-level due to the pitch angle increase. Small oscillations on the power injection can be seen being provoked by the pitch angle adjustment. On the bottom graphic, the results for the case $\mathrm{B}$ are depicted. In this case, the power reduction is achieved by the wind turbine through the aforementioned pitch angle adjustment together with the active power dissipation at the chopper resistors. The time response of chopper resistors is smaller than the pitch regulation. This factor is crucial on an effective power reduction. In fact, this characteristic is the reason for the smoother response of this strategy. Also, at $\mathrm{t}=30 \mathrm{~s}$ it is possible to verify that the chopper resistor is disconnected due to the thermal protection trip. After the chopper disconnection, a small disturbance is still occurring however with small magnitude. This disturbance is induced by the pitch angle regulation that adapts the generation output to meet the DC voltage pre-disturbance value. 


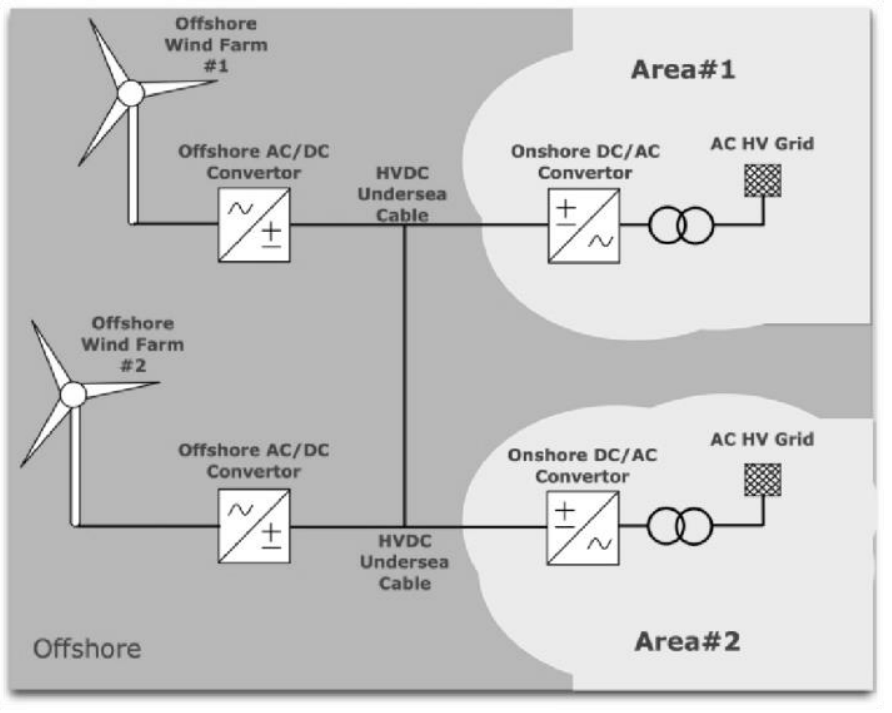

Fig. 8. MTDC test system.
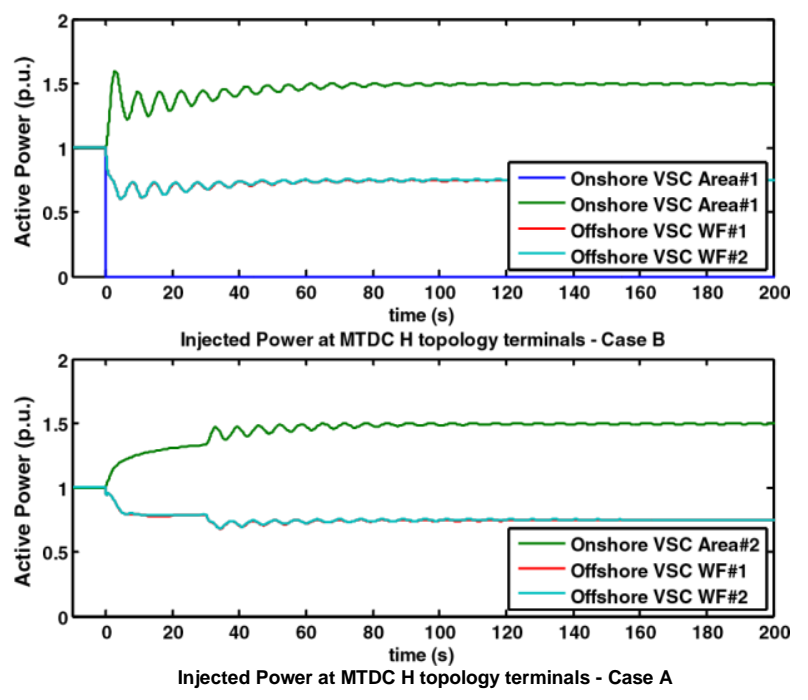
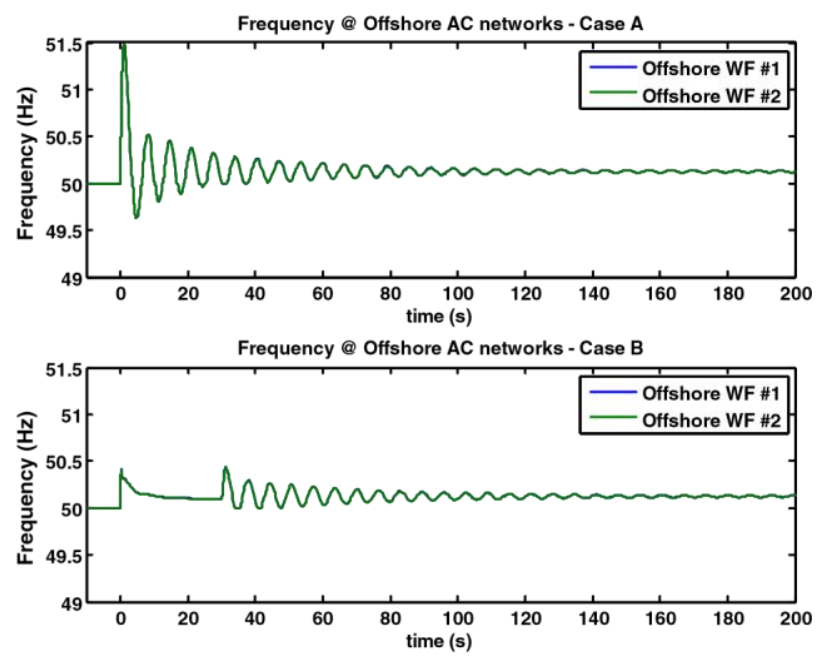

Fig. 11. Frequency at offshore WF AC grids
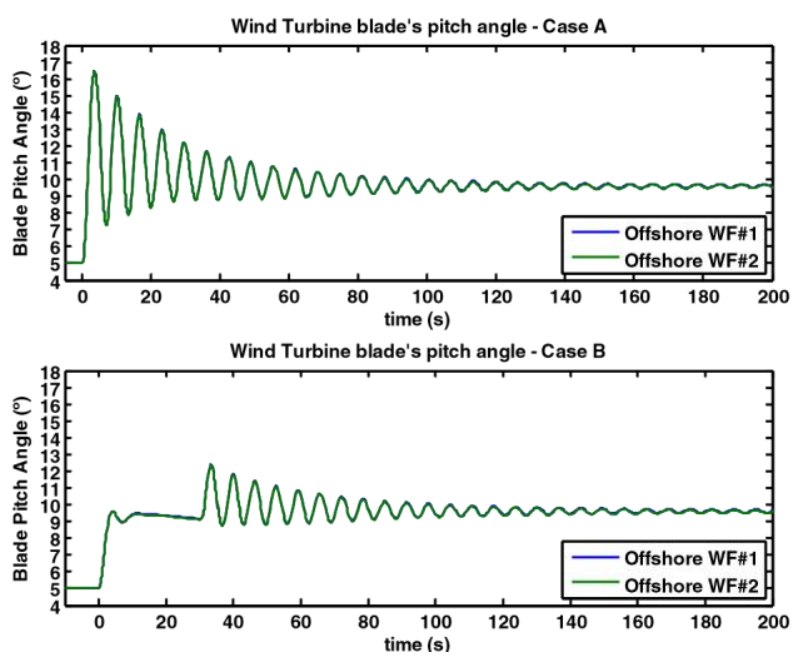

Fig. 10. DC voltage profile at MTDC grid terminals Fig. 12. Wind turbines' pitch angle

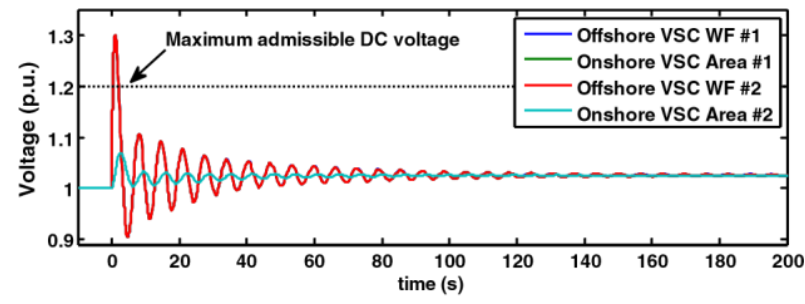

DC Voltage Profile @ MTDC grid terminals - Case B

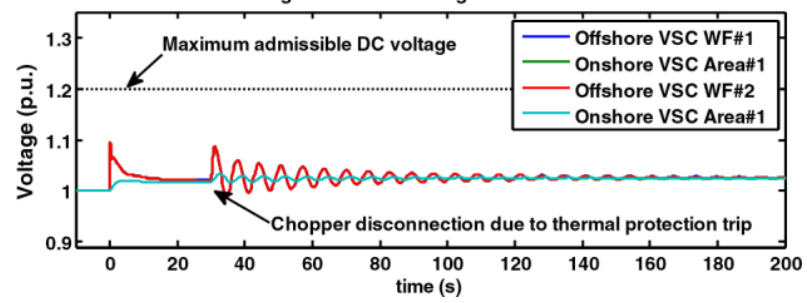

Fig. 9. Injected power at MTDC grid terminals 

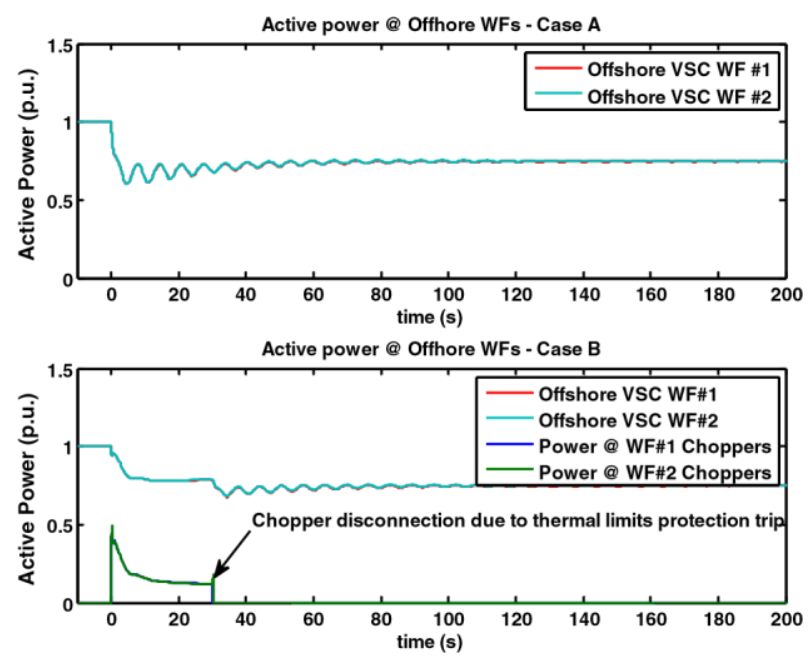

Fig. 13. Active power at offshore WF level

\section{FINAL REMARKS}

This paper assessed the dynamic phenomena associated to the operation of a multi-terminal DC grid following the loss of an onshore converter. From the power balance perspective, the loss of a converter culminates on an active power surplus trapped in the DC grid. This specific type of power imbalance may lead to DC overvoltage which has to be controlled to prevent damaging several components. A communication-free control scheme has been developed, endowing offshore wind turbines on the participation of active power balance mechanisms to mitigate the DC voltage rising effect. The approach consisted on taking advantage of the DC voltage rise and replicating it as an offshore frequency increase. Consequently, offshore wind turbines can be made responsive to offshore AC frequency variations in order to cope with the desired control action. Two strategies based on offshore AC frequency control for WT power reduction were tested. The first, named as case A consisting on the WT pitch control to achieve the active power injection reduction. The second, name as case B, with the same characteristics of the case A, was enhanced in order to incorporate the participation of WT level chopper resistors in order to achieve a faster response regarding the DC grid power balance and voltage rise mitigation..

Extensive simulation results demonstrate the effectiveness of the proposed control solutions, which are able to mitigate the DC voltage rise effect without relying on fast communication links.

\section{REFERENCES}

[1] EWEA, Wind in Power - 2011 European Statistics, The European Wind Energy Association, 2012.

[2] J. De Decker, and A. Woyte, "Review of the various proposals for the European offshore grid," Renewable Energy, vol. 49, no. 0, pp. 58-62, 2013.

[3] European Union Project TWENTIES. "http://www.twentiesproject.eu," October 2012, 2012.

[4] Inteligent Energy Europe. "Tradewind Project http://www.tradewind.eu " October, 2012.

[5] K. Bell, D. Cirio, A. M. Denis, L. He, C. C. Liu, G. Migliavacca, C. Moreira, and P. Panciatici, "Economic and technical criteria for designing future off-shore HVDC grids," in Innovative Smart Grid Technologies Conference Europe (ISGT Europe) 2010 IEEE PES, 2010, pp. 1-8

[6] O. Gomis-Bellmunt, J. Liang, J. Ekanayake, R. King, and N. Jenkins, "Topologies of multiterminal HVDC-VSC transmission for large offshore wind farms," Electric Power Systems Research, vol. 81, no. 2, pp. 271-281, 2011

[7] O. Gomis-Bellmunt, J. Liang, J. Ekanayake, and N. Jenkins, "Voltagecurrent characteristics of multiterminal HVDC-VSC for offshore wind farms," Electric Power Systems Research, vol. 81, no. 2, pp. 440-450, 2011.

[8] S. Cole, J. Beerten, and R. Belmans, "Generalized Dynamic VSC MTDC Model for Power System Stability Studies," Power Systems, IEEE Transactions on, vol. 25, no. 3, pp. 1655-1662, 2010.

[9] $\mathrm{ABB}$, "ABB solves 100-year-old electrical puzzle - new technology to enable future DC grid-Development of a DC breaker for high voltage transmission will help shape the grid of the future," ABB news, 2012.

[10] L. Jun, J. Tianjun, O. Gomis-Bellmunt, J. Ekanayake, and N. Jenkins, "Operation and Control of Multiterminal HVDC Transmission for Offshore Wind Farms," Power Delivery, IEEE Transactions on, vol. 26 no. 4, pp. 2596-2604, 2011.

[11] B. Silva, C. L. Moreira, L. Seca, Y. Phulpin, and J. A. Pecas Lopes, "Provision of Inertial and Primary Frequency Control Services Using Offshore Multiterminal HVDC Networks," Sustainable Energy, IEEE Transactions on, vol. 3, no. 4, pp. 800-808, 2012.

[12] G. Ramtharan, A. Arulampalam, J. B. Ekanayake, F. M. Hughes, and N. Jenkins, "Fault ride through of fully rated converter wind turbines with AC and DC transmission," Renewable Power Generation, IET, vol. 3, no. 4 , pp. 426-438, 2009.

[13] C. Feltes, H. Wrede, F. W. Koch, and I. Erlich, "Enhanced Fault RideThrough Method for Wind Farms Connected to the Grid Through VSCBased HVDC Transmission," Power Systems, IEEE Transactions on, vol. 24, no. 3, pp. 1537-1546, 2009.

[14] O. Gomis-Bellmunt, A. Egea-Alvarez, A. Junyent-Ferre, L. Jun, J. Ekanayake, and N. Jenkins, "Multiterminal HVDC-VSC for offshore wind power integration," in Power and Energy Society General Meeting, 2011 IEEE, 2011, pp. 1-6.

[15] O. B. J.Liang, J.Enakayake, N.Jenkins, "Control of multi-terminal VSCHVDC transmission for offshore wind power," 2009.

[16] S. M. Muyeen, R. Takahashi, T. Murata, and J. Tamura, "A Variable Speed Wind Turbine Control Strategy to Meet Wind Farm Grid Code Requirements," Power Systems, IEEE Transactions on, vol. 25, no. 1, pp. 331-340, 2010.

\section{BIOGRAPHIES}

B. Silva is a Researcher in the Power Systems Unit of INESC Porto. He obtained a M.Sc. in Electrical Engineering from the Faculty of Engineering of University of Porto (FEUP) in 2009. He is currently pursuing a Ph.D. degree from the MIT Portugal Program on Sustainable Energy Systems at FEUP. His main research interests are focused on wind power integration and HVDC systems FACTS devices and Smart Grids.

C. L. Moreira is a Senior Researcher and Smart Grid Area leader in the Power Systems Unit of INESC Porto since 2010. He is also Assistant Professor in the Department of Electrical Engineering of FEUP. He obtained the Electrical Engineering degree (5-year course) in 2003 and the Ph.D. in 2008, both from the FEUP. His main research interests are focused on smart grids, wind power integration, HVDC systems and FACTS devices.

H.Leite received his Electrical Engineering degree from University of Porto, Portugal in 2000 and the $\mathrm{PhD}$ degree in Electrical Engineering from The University of Manchester, UK, in 2004. He joined university of Porto as a Lecturer in 2005. His research interests include Distribution Generation Integration, Electric Power Systems and Power Systems Protection. 